\title{
The Tuning of Chitosan's Hydrophilicity by Changing the PEG Content Grafted on the Chitosan Backbone
}

\author{
DANIELA AILINCAI* \\ "Petru Poni" Institute of Macromolecular Chemistry, 41A Gr. Ghica Voda Alley,700487, Iasi, Romania
}

\begin{abstract}
The study presents the synthesis and characterization of two series of hydrophilic chitosan derivatives, based on imine or amine linkage through PEGylation. The impact of PEGylation on the morphology and supramolecular architecture along with the wettability were studied. The obtained results proved that PEGylation is an appropriate method for tuning chitosan's hydrophilicity. Adding to that, the properties of the derivatives can be designed according to the targeted application.
\end{abstract}

Keywords: chitosan, PEGylation, hydrophilicity, imines, amines

\section{Introduction}

In the recent years, the researchers' attention has been directed towards the exploitation of polysaccharides, due to their extraordinary properties which recommend them for a large variety of applications [1,2]. Among them, chitosan occupies a special place, being widely used in the design and development of materials and biomaterials with advanced functions and applications [3,4], being involved in each application field, from agriculture [5,6], waste water treatment $[7,8]$, diapers industry [9] to drug delivery [10-13], gene therapy [14] or bioengineering [15,16].

Chitosan presents not only versatile properties, but also important therapeutic characteristics, such as: hypolipidemic and hypoglycemic effect, hemostatic, antimicrobial and antitumoral activity and mucoadhesivity and that is why, when applications in medicine or human related healthcare are required, chitosan represents one of the most suitable choices [17-19].

From the chemical point of view, chitosan is composed of randomly distributed $\beta-(1-4)$-Dglucosamine and $\mathrm{N}$-acetyl-D-glucosamine, being obtained by chitin deacetylation usually with sodium hydroxide [20]. The presence in its structure of the primary amine units makes it versatile also in terms of the chemical reactivity, chitosan representing a large workbench for the development of new classes of materials.

Even though chitosan is largely used in biomedicine, its most important drawback is represented by its poor wettability, being known that materials' biocompatibility and in vivo compliance are related to the water content [21]. In order to improve chitosan's hydrophilicity, different methods were used, among which PEGylation is the most commonly used and easily to be achieved. Different PEGylated chitosan derivatives were reported in the literature, using chitosan and PEG with different molecular weights (Table 1), in order to achieve appropriate characteristics for chitosan, adequate for bioapplications. Usually, chitosan's modifications with PEG side chains were achieved at the amine group of chitosan, through amide linkages, but PEG-g-chitosan at the hydroxyl group from the primary alcohol from chitosan was also reported [29].

Table 1. PEGylated chitosan derivatives: characteristics of chitosan and PEG

\begin{tabular}{|c|c|c|c|c|}
\hline PEGylated chitosan derivative & Chitosan reactive group & $\mathrm{MW}_{\text {Chitosan }}$ (Da) & $\mathrm{MW}_{\mathrm{PEG}}(\mathrm{Da})$ & Ref. \\
\hline PEG-g-chitosan & Amine & $\begin{array}{l}28900 \\
82000\end{array}$ & $\begin{array}{c}1900 \\
500\end{array}$ & [22] \\
\hline PEG-g-chitosan & Amine & 11000 & $\begin{array}{c}750 \\
2000 \\
5000\end{array}$ & {$[23]$} \\
\hline PEG-g-chitosan & Amine & 70000 & 5000 & [24] \\
\hline PEG-g-chitosan & Amine & 400000 & 2000 & {$[25]$} \\
\hline
\end{tabular}

$\overline{\text { *email: ailincai.daniela@icmpp.ro }}$ 


\begin{tabular}{|c|c|c|c|c|}
\hline PEG-g-chitosan & Amine & unknown & 2000 & [26] \\
\hline PEG-g-chitosan & Amine & $\begin{array}{c}50000 \\
190000\end{array}$ & 2000 & [27] \\
\hline PEG-g-chitosan & Amine & 305000 & 2000 & [28] \\
\hline PEG- $g$-chitosan & Hydroxyl & 400000 & 2000 & {$[29]$} \\
\hline
\end{tabular}

In this context, the present study reports the synthesis of two series of chitosan derivatives with improved hydrophilicity by PEGylation through imine or amine linkages, which brings supplementary advantages such as: increased biocompatibility, stealth behavior and prolonged blood circulation time [30-32]. One series was obtained by the acid condensation reaction of chitosan's amino groups with PEG-monoaldehyde in different molar ratios of their functionalities, giving rise to imino-chitosan derivatives with different PEG content. The second series was synthesized starting from the previous series, by reductive amination, when amino-chitosan derivatives were obtained. The impact of the PEGylation on the morphology, supramolecular architecturing and wettability was evaluated by SEM, $\mathrm{X}$-ray diffraction and water to air contact.

\section{Materials and methods}

\subsection{Materials}

Low molecular weight chitosan (217.74 kDa, DA: 85\%), O-[2-(6-Oxocaproylamino)ethyl]-O'methylpolyethylene glycol 2000, sodium borohydride $\left(\mathrm{NaBH}_{4}\right)$, acetic acid and ethanol were purchased from Sigma Aldrich and used as received.

\subsection{The synthesis of PEGylated chitosan derivatives}

Two series of PEGylated chitosan derivatives, 5 compounds each, were obtained by the acid condensation between chitosan and PEG-aldehyde, by changing the molar ratios of their reactive groups (amine and aldehyde) from 50/1 to 10/1 (Table 2). One series is based on reversible imine linkages (I1I5 series), while the other one was obtained by the reductive amination reaction of the first one, with sodium borohydride, which led to the obtaining of PEGylated chitosan derivatives based on amine linkages (A1-A5 series) (Scheme 1).

2.2.1 The synthesis of the imino-PEGylated chitosan derivatives (I1-I5) was done by the following experimental procedure: $60 \mathrm{mg}$ of chitosan were dissolved in an acetic acid aqueous solution $(21 \mu \mathrm{L}$ acetic acid in $3 \mathrm{~mL}$ water). When chitosan's dissolution was completed, the corresponding amount of PEG monoaldehyde in ethanol, according to the table, was added, in order to obtain different PEG content grafted on the chitosan backbone. After $3 \mathrm{~h}$ of magnetic stirring at $55^{\circ} \mathrm{C}$, the reaction mixture was cooled down at room temperature and freeze in liquid nitrogen and submitted to lyophilization.

2.2.2 The synthesis of the amino-PEGylated chitosan derivatives (A1-A5) was done following the next experimental procedure: $60 \mathrm{mg}$ of lyophilized I1-I5 compounds were added into a solution of $\mathrm{NaBH}_{4}$ in ethanol, according to Table 1. The heterogeneous system was kept under magnetic stirring for $48 \mathrm{~h}$. After the reaction time, the $\mathrm{NaBH}_{4}$ solution was removed and the solid was washed three times with pure ethanol.

Table 2. The composition of PEGylated chitosan's derivatives

\begin{tabular}{|l|l|l|l|l|l|l|l|}
\hline Samples & Sample code & $\begin{array}{l}\mathbf{m}_{\text {chitosan }} \\
(\mathbf{m g})\end{array}$ & $\begin{array}{l}\mathbf{V}_{\text {water }} \\
(\mathbf{m L})\end{array}$ & $\begin{array}{l}\mathbf{V}_{\text {acetic acid }} \\
(\boldsymbol{\mu L})\end{array}$ & $\begin{array}{l}\mathbf{m}_{\text {PEG }} \\
(\mathbf{m g})\end{array}$ & $\begin{array}{l}\mathbf{V}_{\text {ethanol }} \\
(\mathbf{m L})\end{array}$ & $\begin{array}{l}\mathbf{m}_{\text {NaBH4 }} \\
(\mathbf{m g})\end{array}$ \\
\hline \multirow{5}{*}{ Imino-PEGylated chitosan } & $\mathbf{I 1}$ & 60 & 3 & 21 & 12 & 1.2 & - \\
& $\mathbf{I 2}$ & 60 & 3 & 21 & 15.1 & 1.51 & - \\
\cline { 2 - 9 } & $\mathbf{I 3}$ & 60 & 3 & 21 & 20.2 & 2.02 & - \\
& $\mathbf{I 4}$ & 60 & 3 & 21 & 30.3 & 3.03 & - \\
\cline { 2 - 9 } & $\mathbf{I 5}$ & 60 & 3 & 21 & 60.6 & 6.06 & - \\
\hline Amino-PEGylated chitosan & $\mathbf{A 1}$ & 60 & - & - & - & 4.45 & 2.2 \\
\hline
\end{tabular}




\begin{tabular}{|l|l|l|l|l|l|l|l|}
\hline A2 & 60 & - & - & - & 5.8 & 2.9 \\
A3 & 60 & - & - & - & 7.6 & 3.8 \\
\hline A4 & 60 & - & - & - & 11.4 & 5.7 \\
A5 & 60 & - & - & - & 22 & 11 \\
\hline
\end{tabular}

\subsection{Methods}

Lyophilization. The PEGylated chitosan derivatives were obtained by freezing them in liquid nitrogen, after which they were lyophilized using a LABCONCO Free Zone Freeze Dry System equipment, in working conditions $-54^{\circ} \mathrm{C}$ and 1.510 mbar, for $24 \mathrm{~h}$.

ATR-FTIR spectra of the I1-I5 and A1-A5 series were recorded using a FTIR Bruker Vertex 70 Spectrophotometer equipped with a ZnSe single reflection ATR accessory.

Wide angle X-ray diffraction (WAXD) was performed on a Bruker D8 Advance diffractometer at $36 \mathrm{kV}$ and $30 \mathrm{~mA}$, using $\mathrm{Ni}$ filtered $\mathrm{Cu}-\mathrm{Ka}$ radiation $(\lambda=0.1541 \mathrm{~nm})$. The diffractograms were recorded in the 2-40 degrees range, at room temperature, on pellets obtained by pressing a certain amount of sample using a hydraulic press $\left(5 \mathrm{~N} / \mathrm{m}^{2}\right)$.

The investigations of the supramolecular architecture of the systems was realized by polarized optical microscopy (POM), using a Leica DM 2500 microscope.

The morphology of the samples was evaluated with a field emission scanning electron microscope (Scanning Electron Microscope SEM EDAX - Quanta 200) at accelerated electron energy of $10 \mathrm{eV}$.

The static contact angle for I1-I5 series was measured using a CAM-200 instrument from KSV Finland, by the sessile drop method, at room temperature and controlled humidity. The measurements were performed in $10 \mathrm{~s}$ after placing $1 \mu \mathrm{L}$ drop of water on film surface and the contact angle was measured by fitting the drop profile using the Young-Laplace equation [33]. The contact angle was measured 5 times on different places of the surface, and after that the average value was calculated.

\section{Results and discussions}

The study presents the synthesis and characterization of two series of imino and amino-PEGylated chitosan derivatives. The first series was obtained by the acid condensation of chitosan's amine groups with PEG monoaldehyde (coded I1-I5), while the second series was obtained by the reductive amination of the first one (coded A1-A5) (Scheme 1). The main idea was to improve chitosan's hydrophilicity in order to make it even more suitable for bioapplications and to establish a PEG content - hydrophilicity relationship.

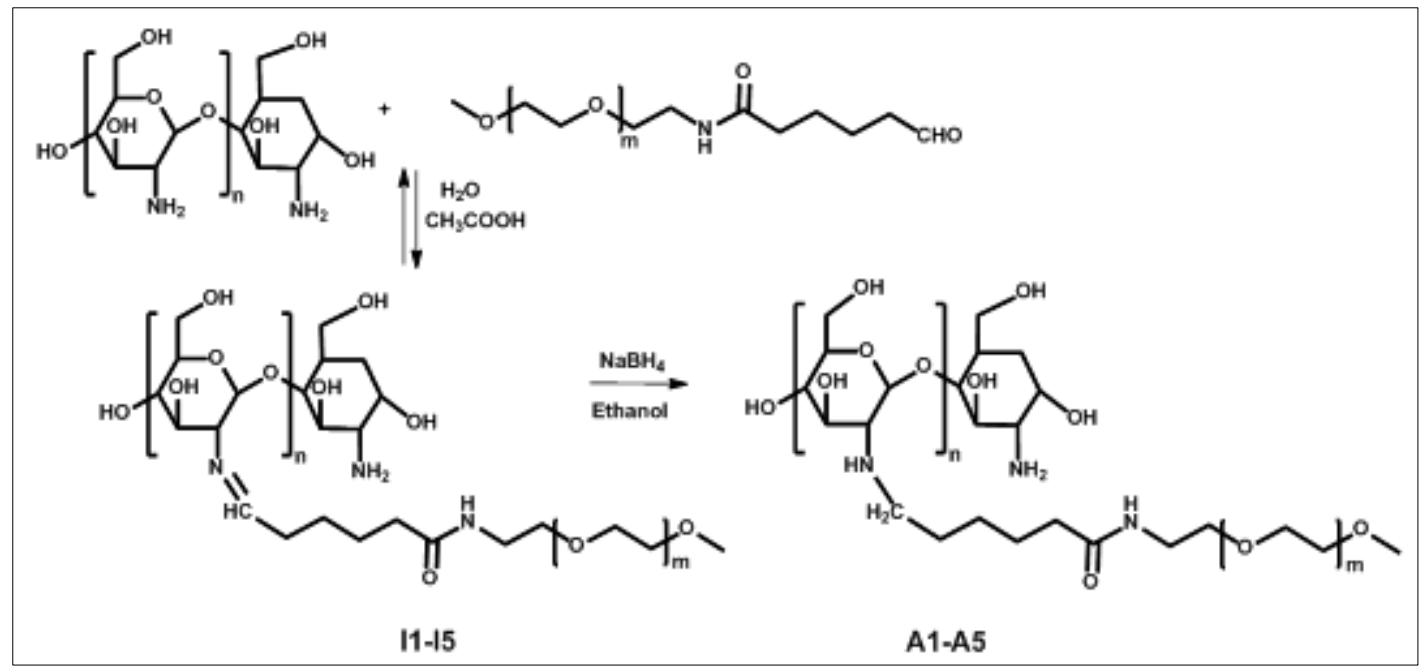

Scheme 1. The synthesis of imino and amino-PEGylated chitosan derivatives 


\subsection{The characterization of PEGylated chitosan derivatives}

\subsubsection{Structural characterization of imino and amino-PEGylated chitosan derivatives by FTIR}

In order to validate the success of the acid condensation reaction between the amino groups of chitosan and the aldehyde group of PEG-aldehyde, the FTIR spectra were recorded for all samples, reagents and reaction products. As it could be observed, the FTIR spectrum of chitosan reveals that its morphology is governed by intra and intermolecular hydrogen bonds which are reflected in the 2700$3700 \mathrm{~cm}^{-1}$ and 1200-1500 $\mathrm{cm}^{-1}$ spectral regions (Figure 1a, b). Moreover, the chitosan FTIR spectrum presented a sharp peak at $1635 \mathrm{~cm}^{-1}$, corresponding to the secondary amide stretching. PEG-aldehyde presented intense bands at $2882 \mathrm{~cm}^{-1}$ and 1460 and $1340 \mathrm{~cm}^{-1}$, corresponding to the $\mathrm{C}-\mathrm{H}$ stretching and bending respectively, while at $1724 \mathrm{~cm}^{-1}$ appeared the vibration corresponding to the stretching of the $\mathrm{C}=\mathrm{O}$ group. In comparison, in the spectra of the imine-PEGylated chitosan derivatives (I1-I5), significant changes could be observed, consequence of the chemical and physical interactions established between the two reagents. Firstly, in the fingerprint region appeared a new band at 1642 $\mathrm{cm}^{-1}$ (Figure 1a), which corresponds to the group stretching vibrations of the newly formed imine $[34,35]$. Moreover, the band which corresponds to the $\mathrm{C}=\mathrm{O}$ stretching vibration from $\mathrm{PEG}$-aldehyde, completely disappeared in the spectrum of the chitosan derivatives, indicating its complete consumption in the condensation reaction with the amino groups of chitosan. On the other side, significant modifications appeared between $3700-2700 \mathrm{~cm}^{-1}$, indicating some morphological changes in chitosan, due to the physical interactions with PEG chains. More precisely, the maximum in chitosan spectrum which is attributed to the intramolecular hydrogen bond is shifted to higher wavenumbers in the spectra of the PEGylated chitosan derivatives, indicating the formation of new hydrogen bonds, due to their physical interaction [34-37].

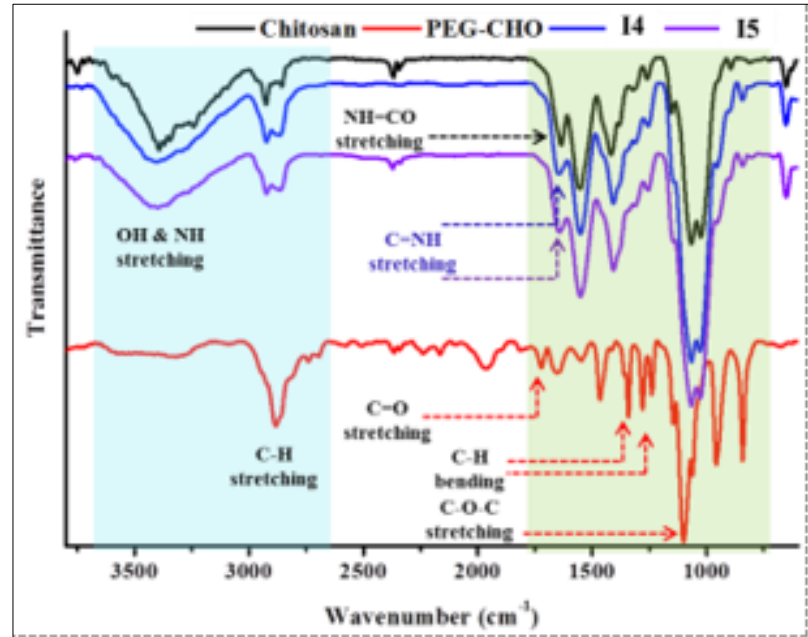

a)

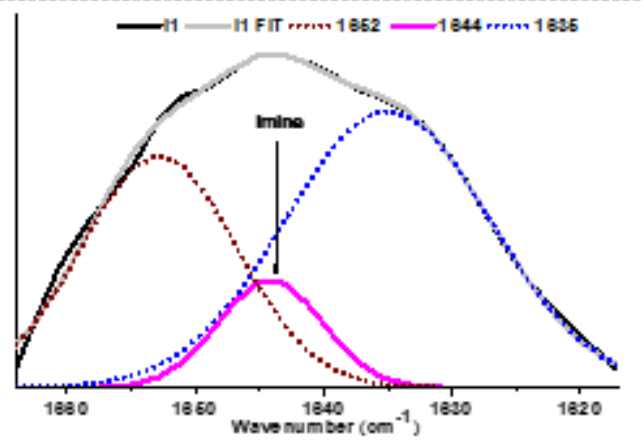

c)

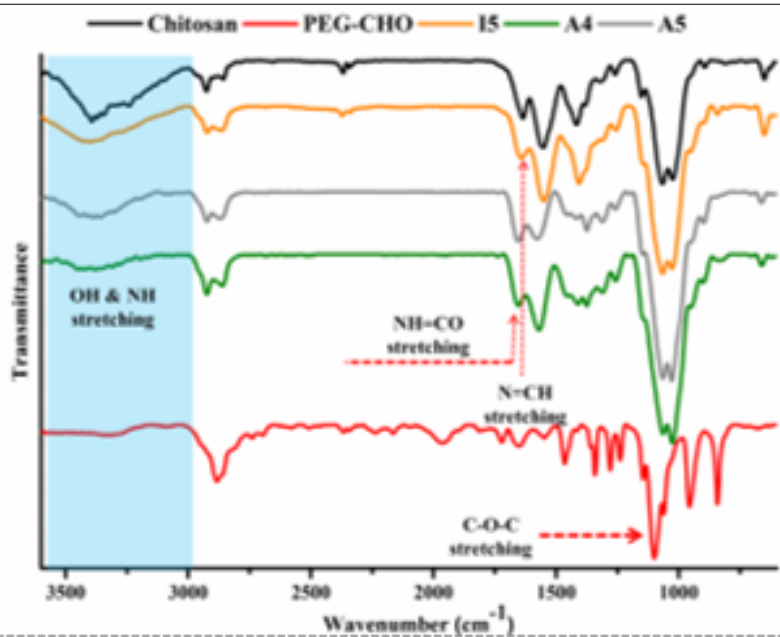

b)

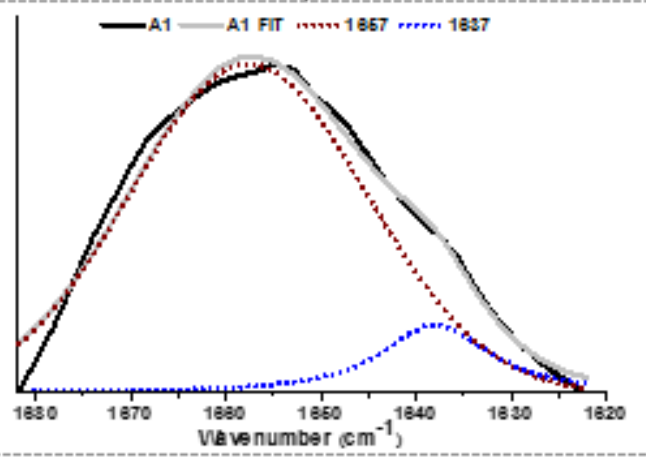

d)

Figure 1. FTIR spectra of chitosan, PEG-aldehyde and some representative imino-PEGylated chitosan derivatives (a) and amino-PEGylated chitosan derivatives (b), deconvoluted FTIR spectrum of I1 derivative (c) and of A1 derivative 
Moreover, amino-PEGylated chitosan derivatives (A1-A5) were also analyzed from the structural point of view by FTIR spectroscopy, revealing the disappearance of the peak corresponding to the imine group, due to its reduction in the reaction with sodium borohydride (Figure 1b). In order to confirm this information, deconvolution of the FTIR spectra was performed. Therefore, after deconvolution, it was observed that the peak from $1642 \mathrm{~cm}^{-1}$ in the imino derivatives spectra was formed from three individual peaks, one of which corresponds to the imine (Figure 1c). In the spectra obtained after deconvolution, for the amine-PEGylated derivatives, it was noticed that this peak disappeared, due to imine conversion into amine (Figure 1d).

\subsubsection{Structural characterization of imine-PEGylated chitosan derivatives by ${ }^{1} \mathrm{H}-\mathrm{NMR}$}

In order to confirm the FTIR data, NMR spectroscopy was used as a complementary method to characterize the PEGylated chitosan derivatives from the structural point of view. For comparison, the NMR spectrum of PEG-aldehyde was also recorded. Therefore, the NMR spectra of the I1-I5 derivatives presented the chemical shifts corresponding to $\mathrm{H} 2-\mathrm{H} 6$ protons from chitosan between 2.5 and $4.5 \mathrm{ppm}$ and the one from the N-acetyl-glucosamine unit at $2.1 \mathrm{ppm}$ and the chemical shifts from PEG-aldehyde between 2-3.5 ppm (Figure 2) [32, 35]. Beside these signals, in the NMR spectra of the chitosan derivatives appeared a new peak at $8.26 \mathrm{ppm}$ which corresponds to the imine proton [35, 38]. Moreover, the NMR spectra confirmed the FTIR data according to which the PEG-aldehyde was completely consumed in the condensation reaction by the absence of any signals above $8.3 \mathrm{ppm}$, considering that the pick characteristic to the monoaldehyde unit from PEG-aldehyde appears at $9.6 \mathrm{ppm}$.

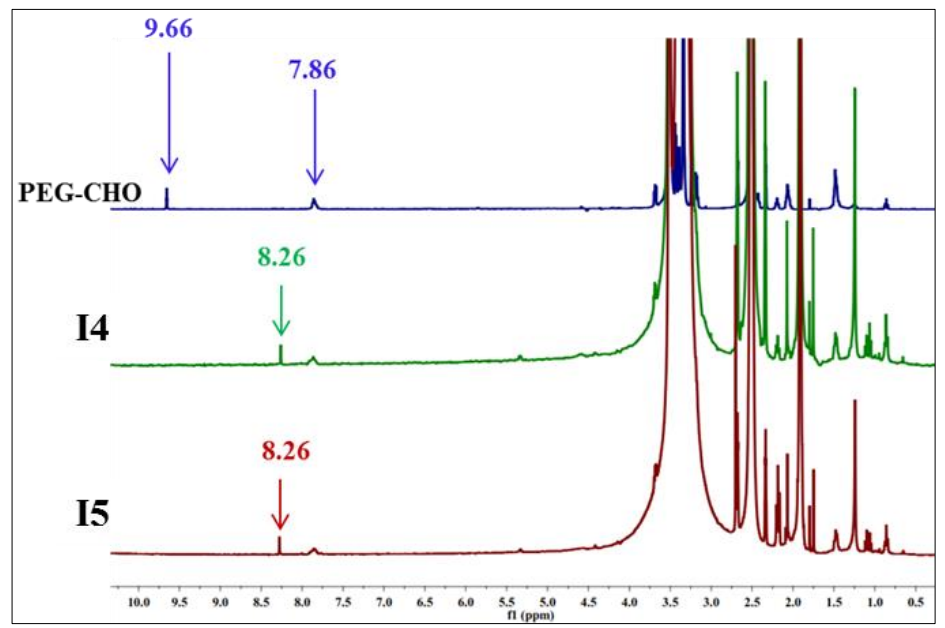

Figure 2. NMR spectra of PEG-aldehyde and some representative imino-PEGylated chitosan derivatives

\subsubsection{The evaluation of the hydrolytic stability of the I1-I5 derivatives in comparison with A1-A5 derivatives by ${ }^{1} \mathrm{H}-\mathrm{NMR}$}

Being known that the imine linkage is reversible in water, the stability of the synthesized derivatives was evaluated by recording their NMR spectra in deuterium oxide at time 0 after their dissolution and after 2 and 24 hours. For comparison, the NMR spectra of the amino-PEGylated chitosan derivatives were recorded in the same manner. As it could be observed in the NMR spectra of the imine derivatives, the fresh dissolved samples displayed the peak corresponding to the chemical shift of the aldehyde proton from PEG-monoaldehyde, indicating that, due to the presence of water molecules, the imine formation equilibrium shifted to reagents (Figure 3a). Moreover, by recording the NMR spectra from time to time, it could be observed that the signal which corresponds to the aldehyde protons increased, while the one corresponding to the imine one decreased (Figure 3b). These data clearly indicated the hydrolytic instability of the imine-PEGylated chitosan derivatives. The amino-PEGylated chitosan derivatives were also evaluated for their hydrolytic stability, when it was observed that even after $24 \mathrm{~h}$, 
the peak corresponding to the aldehyde proton didn't appear in the NMR spectra, sign that the newly formed derivatives were stable in water (Figure 3a).

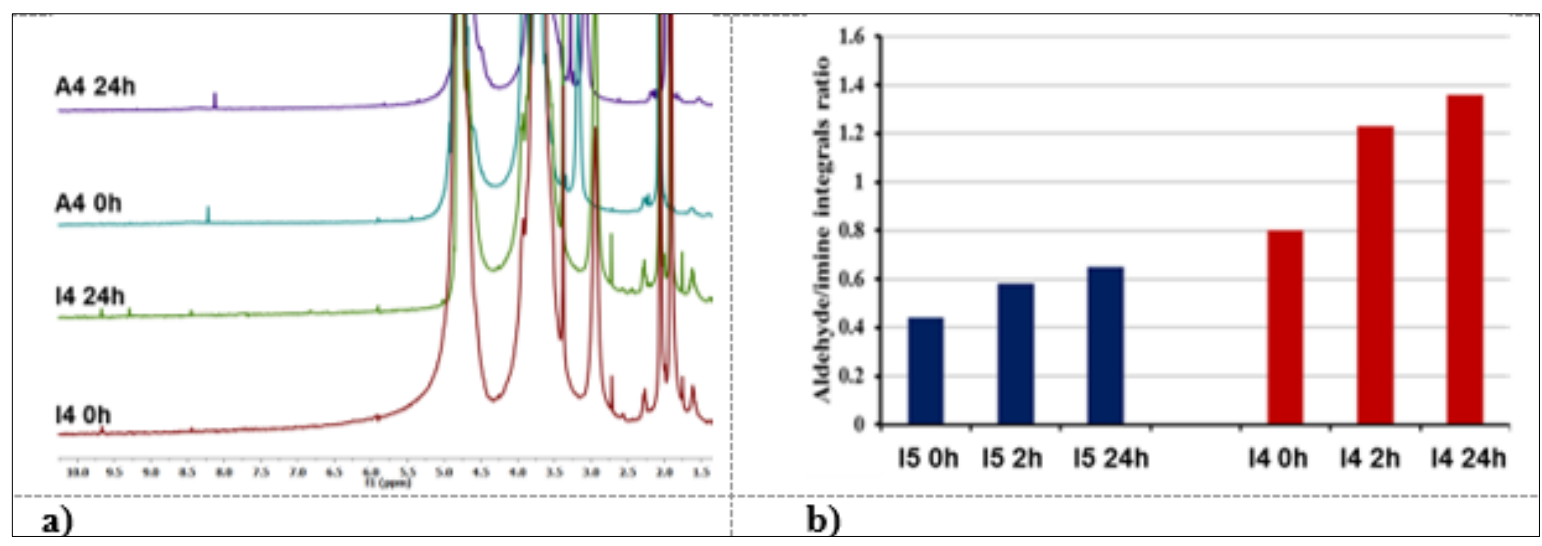

Figure 3. NMR spectra of $\mathbf{I} 4$ and $\mathbf{A} 4$ derivatives in $\mathrm{D}_{2} \mathrm{O}$ at different moments after dissolution (a) and variation of aldehyde/imine integrals ratio (b)

\subsubsection{Supramolecular characterization by X-ray diffraction}

Wide angle X-ray diffraction was used in order to characterize the I1-I5 and A1-A5 series from the supramolecular point of view. For comparison, the chitosan's diffractogram was also recorded. The chitosan diffractogram showed the classical pattern of a semi crystalline polymer with a broad band between 5 and 302 theta degrees with two maxima at 13.8 and 202 theta degrees attributed to organized dehydrated clusters entrapped into an amorphous mass of hydrated chitosan (Figure 4a) [39]. In comparison to this, the diffractograms of the imine-PEGylated chitosan derivatives presented some changes in terms of reflections number and position. First, it could be observed the presence of new reflections at 19 and 232 theta degrees, which indicate the presence of PEG side chains on chitosan backbone [40]. Secondly but equally important is the shifting of the shoulder from chitosan diffractogram, from 13.82 theta degrees to lower angles (12 2 theta degrees) and therefore, according to Bragg's law, to higher distances (Table 3). This may indicate that the presence of PEG side chains on the chitosan backbone hinder their packing in clusters with higher degrees of ordering [41]. By comparing the supramolecular arrangement of the imine-PEGylated chitosan derivatives to the one of the amine-PEGylated chitosan derivatives, no changes were observed, the reflection number and position remaining the same in the case of all samples (Figure 4a).

Table 3. X-ray data for chitosan and the obtained PEGylated chitosan derivatives

\begin{tabular}{|l|l|l|}
\hline Sample & Reflexion (20) & Distance (nm) \\
\hline \multirow{2}{*}{ Chitosan } & 13.8 & 6.46 \\
\cline { 2 - 3 } & 20 & 4.5 \\
\hline \multirow{3}{*}{ I1 - I5 \& A1 - A5 } & 12.2 & 7.29 \\
\cline { 2 - 3 } & 19 & 4.73 \\
\cline { 2 - 3 } & 23 & 3.94 \\
\hline
\end{tabular}

By observing the samples under polarized light, a birefringent texture was observed, indicating a certain degree of ordering of the samples, in agreement with the semicrystalline state demonstrated by the X-ray data (Figure 4b) [42, 43]. 


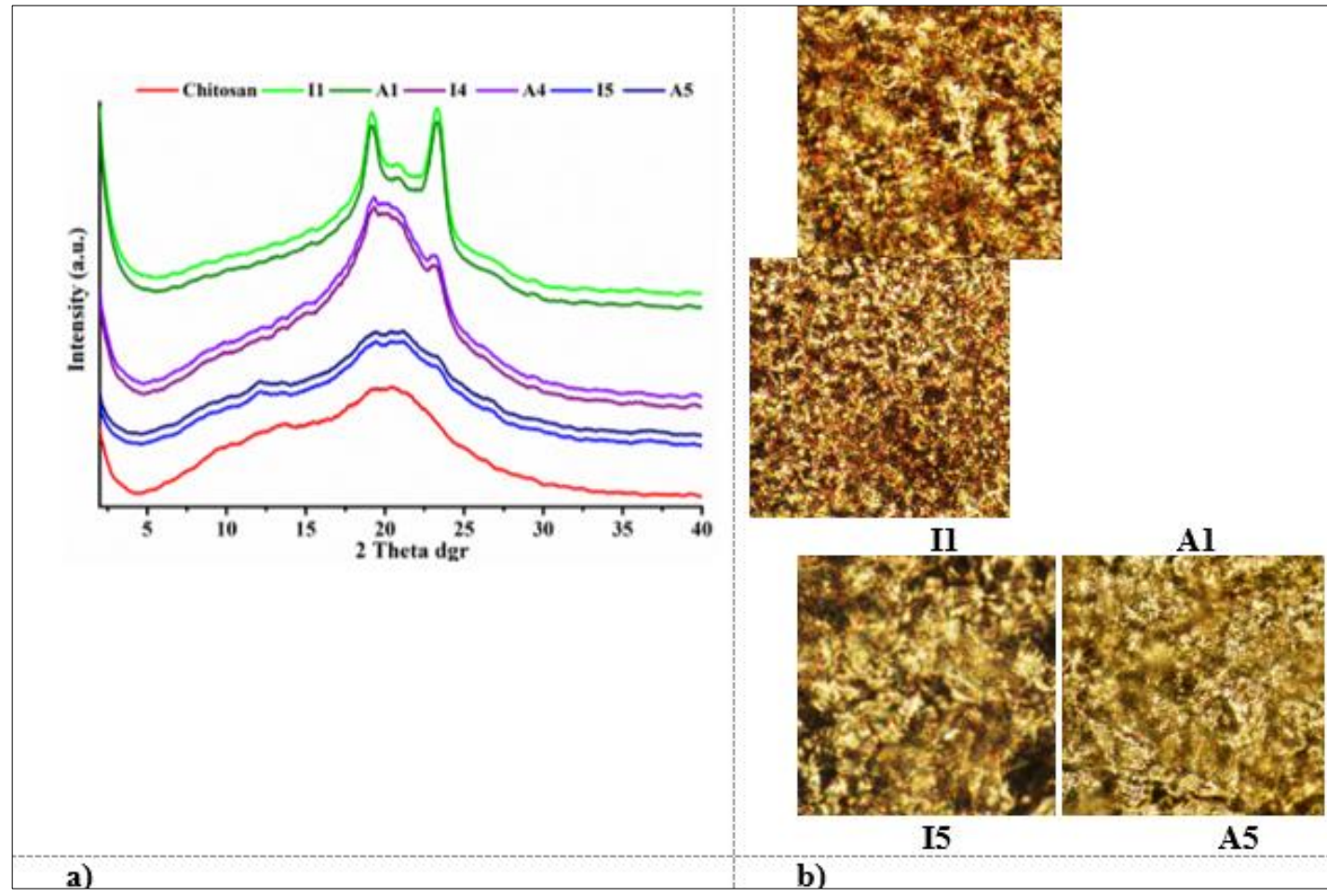

Figure 4. WXRD diffractograms (a) and POM images (b) of some representative imine and amine-PEGylated chitosan derivatives

\subsubsection{Morphological characterization by SEM}

In order to evaluate the morphology of the samples, they were analyzed by scanning electron microscopy. For comparison, chitosan was also analyzed by SEM and used as reference. As it could be observed, compared to the chitosan sample, all the imino-PEGylated derivatives presented a porous morphology, regardless the PEG content, attributed to the hydrogelling effect induced by the PEGylation (Figure 5). Moreover, as expected, the same porous morphology was observed also for the aminoPEGylated chitosan derivatives. The size of the pores depended mainly on the PEG content and not on the presence of imine or amine linkages. As already mentioned in the materials and methods section, the amino-PEG-ylated derivatives were obtained by the reductive amination in heterogeneous systems of the imine-PEGylated ones. This could be the reason why, the morphology of the samples after reductive amination, was kept unchanged. The size of the pore was micrometric in all cases, the samples $\mathbf{I} 2$ and A2 having a mean diameter of $12 \mu \mathrm{m}$, while the samples $\mathbf{I 4}$ and $\mathbf{A 4}$ had a mean diameter of $10 \mu \mathrm{m}$.
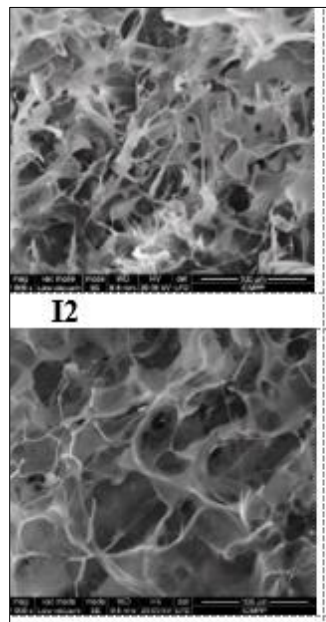

A2

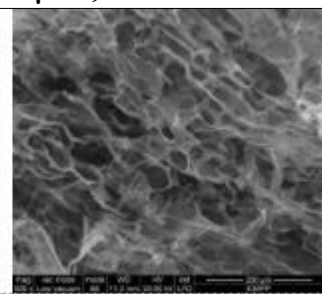

13

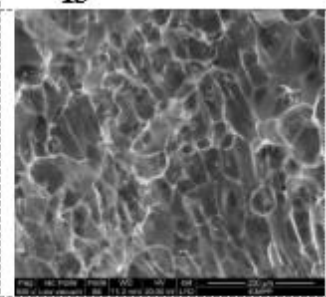

A3

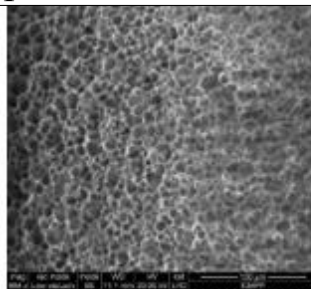

14

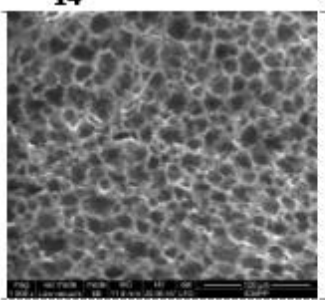

A4

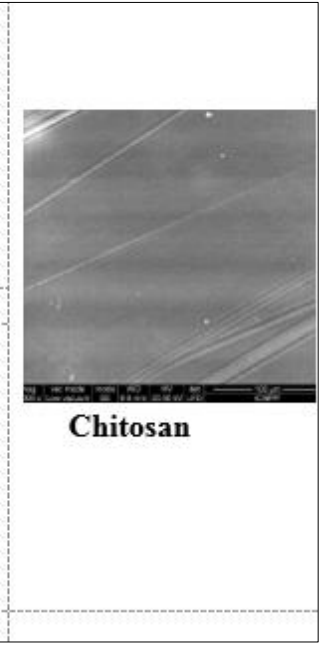

Figure 5. SEM images of some representative imine and amine PEGylated Chitosan derivatives and of chitosan reference 


\subsubsection{The contact angle of PEGylated chitosan derivatives}

In order to evaluate the success of theoretical design according to which the wettability of the samples is governed by the PEG content, their water to air contact angle was measured and compared with the one of chitosan. Therefore, chitosan presents a water to air contact angle of $104 \mathrm{dgr}$, indicating a quite hydrophobic surface, this value exceeding the one of $90 \mathrm{dgr}$, which is known as being the superior limit of the moderate wettability domain (Figure 6) [41].

By grafting PEG side chains on the chitosan backbone, the wettability of the samples gradually changed. Therefore, for the samples with lower PEG content (I1-I3), the water to air contact angle remains quite high, around $93 \mathrm{dgr}$, while for the samples I4 and $\mathbf{I 5}$ the obtained values are much lower, I4 reaching the moderate wettability with a value of $85 \mathrm{dgr}$, while the $\mathbf{I 5}$ samples, presents the lower value of water to air contact angle, of $56 \mathrm{dgr}$. All these data reveal that chitosan's hydrophilicity can be improved by PEGylation and even more important than that, it can be tuned by changing the mass ratio between chitosan and PEG (Figure 6b).

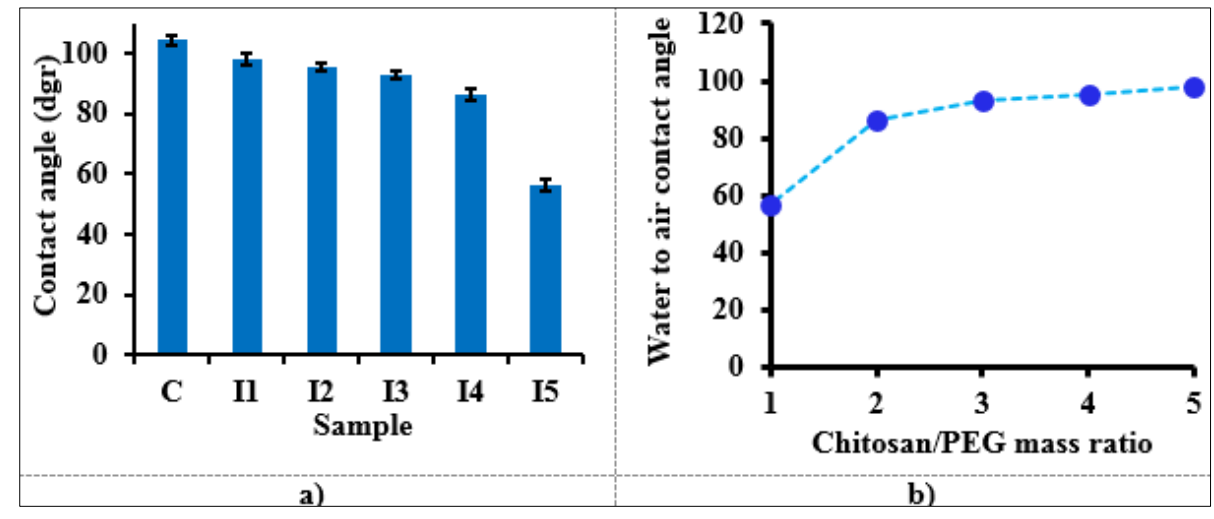

Figure 6. Water to air contact angle for the chitosan, I1-I5 series (a) and its variation with the chitosan/PEG mass ratio from chitosan derivatives. The values are presented as the mean of three individual measurements \pm S.D

\section{Conclusions}

Ten chitosan derivatives based on imine or amine linkages were obtained by varying the molar ratio between the amino and aldehyde reactive groups of the reagents. FTIR and NMR spectroscopy demonstrated the forming of imine linkages or of the amine linkages, respectively. WXRD and POM demonstrated that all chitosan derivatives presented a certain degree of ordering, but no packing of the PEG side chains in ordered clusters was observed. All the samples presented porous morphology regardless they were based on imine or amine linkages, as revealed by SEM. The obtained water to air contact angle values for PEGylated chitosan derivatives showed an increasing trend as the content of the PEG decreased, from 56 to $93 \mathrm{dgr}$, indicating PEGylation as an appropriate pathway to tune the chitosan's hydrophilicity.

Acknowledgement. This work was supported by the Romanian National Authority for Scientific Research MEN - UEFISCDI (grant number PN-III-P1-1.1-PD-2019-1021) and by the project H2020MSCA-RISE-2019: Smart Wound Monitoring Restorative Dressings (SWORD) (no. 873123).

\section{References}

1. YU Y., SHEN M., SONG Q., XIE J., Biological activities and pharmaceutical applications of polysaccharide from natural resources: A review, Carbohydr. Polym.,183, 2017, 91-101.

2. LIU J., WILLFÖR S., XU C., A review of bioactive plant polysaccharides: Biological activities, functionalization, and biomedical applications, Bioact. Carbohydr. Diet. Fibre, 5, 2015, 31-61.

3. RAVI KUMAR M.N.V., A review of chitin and chitosan applications, React. Funct. Polym., 46, 2000, 1-27.

4. RAHBAR M., MORSALI A., MOHAMMAD R., BEYRMABADI S.A., Quantum chemical studies of chitosan nanoparticles as anticancer drug delivery system for decitabine, Cellulose Chem. Technol., 54, 2020, 679-688. 
5. PRIYAL P., MAHENDRA K., NIRMAL D., Chitosan in agricultural context - A review, Bull. Env. Pharmacol. Life Sci., 7, 2018, 87-96.

6. IFTIME M.M., AILIESEI G.L., UNGUREANU E, MARIN L., Designing chitosan based eco-friendly multifunctional soil conditioner systems with urea controlled release and water retention. Carbohydr Polym 223, 2019, 115040.

7.CULITA D., SIMONESCU C.M., PATESCU R.E., STANICA N., Chitosan-based Magnetic Composites - Efficient Adsorbents for Removal of $\mathrm{Pb}(\mathrm{II})$ and $\mathrm{Cu}$ (II) from Aqueous Mono and Bicomponent Solutions, Rev. Chim., 69,(9), 2018, 2323-2330.

8. BEJAN A., DOROFTEI F., CHENG X., MARIN L., Phenothiazine-chitosan based eco-adsorbents: A special design for mercury removal and fast naked eye detection. Int. J. Biol. Macrom., 2020, DOI: 10.1016/j.ijbiomac.2020.07.232.

9.BAOXIAO C., BOYING P., ZHENGKE W., QIAOLING H., Advances in chitosan-based superabsorbent hydrogels, RSC Adv., 7, 2017, 42036.

10. AILINCAI D., TARTAU-MITITELU L., MARIN L., Drug delivery systems based on biocompatible imino-chitosan hydrogels for local anticancer therapy, Drug deliv., 25, 2018, 1080-1090.

11.CRACIUN A.M., MITITELU TARTAU L., PINTEALA M., MARIN L., Nitrosalicyl-iminechitosan hydrogels based drug delivery systems for long term sustained release in local therapy, J. Colloid Interface Sci., 15, 2019, 196-207.

12. AILINCAI D., TARTAU-MITITELU L., MARIN L., Citryl-imine-PEG-ylated chitosan hydrogels - Promising materials for drug delivery applications, Int. J. Biol. Macrom., 2020,

DOI: $10.1016 /$ j.ijbiomac.2020.06.218.

13. IFTIME M., MITITELUL TARTAU L., MARIN L., New formulations based on salicyl-iminechitosan hydrogels for prolonged drug release, Int. J. Biol. Macrom., 2020,

DOI: 10.1016/j.ijbiomac.2020.05.207.

14.YE C., YANG F.T., YEE S.W., WEN M., VENKATRAMAN S., Recent advances in chitosan-based carriers for gene delivery, Mar. Drugs., 17, 2019, 381.

15. SHABNAM M., MOJTABA N.N., PAYAM Z., SEYED H.J., SAMAN S.G., MOHAMMAD R.S., MASOUD M., Chitosan in Biomedical Engineering: A Critical Review, Curr. Stem Cell Res. Ther., 14, 2019, 93-116.

16. IFTIME M.M., ANGHELOIU M., Ultrasonication - a potential method toward chitosan hydrogels, Mater. Plast., 57(2), 2020, 67-77, https://doi.org/10.37358/MP.20.2.5352.

17. SUYEON K., Competitive Biological Activities of Chitosan and Its Derivatives: Antimicrobial, Antioxidant, Anticancer, and Anti-Inflammatory Activities, Int. J. Polym. Sci., 2018, 1708172.

18. RAY FOSTER L.J., HO S., HOOK J., BASUKI M., MARÇAL H., Chitosan as a biomaterial: influence of degree of deacetylation on its physiochemical, material and biological properties, PLoS ONE 10, 2015, e0135153.

19. GUIPING G, ABUL K.A, YUANSHAN L., SUNG W.K., YUN T., GANG L., HONGBING W., Biological effects and applications of chitosan and chito-oligosaccharides, Front. Physiol., 10, 2019.

20.ELIEH-ALI-KOMI D., HAMBLIN M.R., Chitin and chitosan: production and application of versatile biomedical nanomaterials, Int. J. Adv. Res., 4, 2016, 411-427.

21.BAG M.A., VALENZUELA L.M., Impact of the hydration states of polymers on their hemocompatibility for medical applications: a review, Int. J. Mol. Sci. 18, 2017, 1422.

22. CASETTARI L., VLLASALIU D., MANTOVANI G., HOWDLE S.M., STOLNIK S., ILLUM L., Effect of PEGylation on the toxicity and permeability enhancement of chitosan, Biomacromol., 2010, $11,2854-2865$.

23.BACHIR Z.A., HUANG Y., HE M., HUANG L., HOU X., CHEN R., GAO F., Effects of PEG surface density and chain length on the pharmacokinetics and biodistribution of methotrexate-loaded chitosan nanoparticles, Int. J. of Nanomed., 13, 2018, 5657-5671.

24. SAITO H., WU X., MILTON HARRIS J., JINN A., Graft copolymers of poly(ethylene glycol) (PEG) and chitosan, Macromol. Rapid Commun., 18, 1997, 547-550. 
25.MAKUSKA R., GOROCHOVCEVA N., Regioselective grafting of poly(ethylene glycol) onto chitosan through C-6 position of glucosamine units, Carbohydr. Polym., 64, 2006, 319-327.

26. HU X., ZHANG Y., ZHOU H., WAN H., PEGylated chitosan microspheres as mucoadhesive drugdelivery carriers for puerarin, J. Appl. Polym. Sci., 2015, 42623- 42632.

27.CHOI J., PARK J.-S., Design and evaluation of the anticancer activity of paclitaxelloaded anisotropic-poly(lactic-co-glycolic acid) nanoparticles with PEGylated chitosan surface modifications, Int. J. Biol. Macromol., 162, 2020, 1064-1075.

28. KULBOKAITE R., CIUTA G., NETOPILIK M., MAKUSKA R., N-PEG'ylation of chitosan via "click chemistry" reactions, React. Funct. Polym, 69, 2009, 771-778.

29.GOROCHOVCEVA N., MAKUSKA R., Synthesis and study of water-soluble chitosan-Opoly(ethylene glycol) graft copolymers, Eur. Polym. J., 40, 2004, 685-691.

30. MARIN L., BEJAN A., AILINCAI D., BELEI D., Poly(azomethinephenothiazine)s with efficient emission in solid state, European Polym. J., 95, 2018, 127-137.

31.MARIN L., AILINCAI D., CALIN M., STAN D., CONSTANTINESCU C., URSU L., DOROFTEI F., PINTEALA M., SIMIONESCU B.C., BARBOIU M., Dynameric Frameworks for DNA Transfection, ACS Biomaterials Science \& Engineering, 2, 2016, 104-111.

32.CIBOTARU S., SANDU A.I., BELEI D., MARIN L. Water soluble PEGylated phenothiazines as valuable building blocks for bio-materials, Mat. Sci. Eng.: C., 116, 2020, 111216.

33.VASILE C., PASCU M.C., Surfaces Properties of Polymers, Research Signpost, Trivandrum, India, 2007, 179.

34.MARIN L., MORARIU S., POPESCU M.C., NICOLESCU A., ZGARDAN C., SIMIONESCU B.C., BARBOIU M., Out-of-Water constitutional self-organization of chitosan-cinnamaldehyde dynagels. Chem. Eur. J. 20, 2012, 4814-4821.

35. AILINCAI D., MARIN, L. MORARIU S., MARES M., BOSTANARU A.C., PINTEALA M., SIMIONESCU B.C., BARBOIU M., Dual crosslinked iminoboronate-chitosan hydrogels with strong antifungal activity against Candida planktonic yeasts and biofilms. Carbohyd. Polym. 152, 2016, 306316.

36.IFTIME M.M., MORARIU S., MARIN L., Salicyl-imine-chitosan hydrogels: Supramolecular architecturing as a crosslinking method toward multifunctional hydrogels. Carbohyd. Polym. 165, 2017, 39-50.

37.OLARU A.M., MARIN L., MORARIU S., PRICOPE G., PINTEALA M., TARTAU-MITITELU L., Biocompatible chitosan based hydrogels for potential application in local tumour therapy. Carbohyd. Polym. 179, 2018, 59-70.

38. AILINCAI D., PEPTANARIU D., PINTEALA M., MARIN L., Dynamic constitutional chemistry towards efficient nonviral vectors, Mat. Sci. Eng. C, 94, 2019, 635-646.

39. LECETA I., GUERRERO P., IBARBURU I., DUENAS M. T., DE LA CABA K., Characterization and antimicrobial analysis of chitosan-based films. Journal ofFood Engineering, 116, 2013, 889-899.

40. MARIN L., BEJAN A., AILINCAI D., BELEI D., Poly(azomethine-phenothiazine)s with efficient emission in solid state, Eur. Polym. J. 95, 2017, 127-137.

41. IKADA Y., Surface modification of polymers for medical applications. Biomat., 15, 1998, 726-736. 42. BARON M., Definitions of basic terms relating to low-molar-mass and polymer liquid crystals, Pure and App. Chem., 73, 2001, 845-895.

43. CHEN S., WU M., WANG C., YAN S., LU P., WANG S., Developed Chitosan/Oregano Essential Oil Biocomposite Packaging Film Enhanced by Cellulose Nanofibril, Polymers 2020, 12(8), 1780.

Manuscript received: 27.08.2020 